\title{
Arbor
}

\section{Música o matrimonio. Historia oculta de la mujer-música en España}

\section{María Rosa Calvo-Manzano}

Arbor CLXVIII, 663 (Marzo 2001), 407-423 pp.

En la España del siglo que agoniza se han dado tres generaciones de mujeres bien definidas: las madres de la posguerra, sacrificadas y abnegadas, que dejaron, en muchos casos, su profesión por el matrimonio, que entendian como un deber sagrado; mi generación, que es la puente e incomprendida por todos: padres, hermanos, compañeros y amigos, y hasta por la generación actual difícilmente puede entender cómo era la vida de las mujeres hace apenas cuarenta años, y la juventud de nuestros días, resuelta y decidida a compatibilizar su profesión, como primera condición, con el matrimonio.

$S i$, además se tiene en cuenta la pobre consideración social que la música ha tenido hasta hace bien poco tiempo, es fácil imaginar lo difícil que resultaba esta profesión para las mujer de la España reciente.

\section{Música o matrimonio}

No es muy aventurado afirmar que las mujeres de mi generación han supuesto un revulsivo en la conciencia social y laboral española de la segunda mitad del siglo XX. En efecto, las mujeres de la posguerra somos lo que se podría definir como «la generación femenina del 65», porque alrededor de esa fecha una serie de licenciadas y profesionales llegaron a la vida laboral española con una fuerza y pujanza sólo comparable históricamen- 
te, con lo que representaron las excepciones de una Rosalía de Castro, una Concha Espina, una Emilia Pardo Bazán, o una Concepción Arenal.

Un nuevo concepto de la Historia Social y de la Historia de las Mentalidades surge gracias al impulso renovador de una legión de mujeres que lucha denodadamente por ser ellas mismas, al margen de seguir siendo, o renunciando deliberadamente a ser las esposas de...

El siglo XX, iniciado con el advenimiento del reinado de Alfonso XIII, arrastra el espíritu romántico de la centuria decimonónica., aunque el matrimonio del monarca con una inglesa, heredera del más puro estilo victoriano británico, supone un apoyo al espíritu renovador del papel de la mujer en la vida moderna.

De otra parte, el «ideario» de Joaquín Costa es pórtico a un «Regeneracionismo» que influye, no sólo en el pensamiento, sino que se advierte decididamente en todos los movimientos estéticos y artísticos.

Sería injusto silenciar ese mismo espíritu «regeneracionista» en las propuestas musicales de Mitjana, Hilarión Eslava, Barbieri o Soriano Fuentes, que suponen un aire totalmente futurista si se tiene en cuenta que sus postulados se producen en el último tercio del siglo romántico.

Felipe Pedrell, por su parte, propone una vuelta a los valores patrios que transmite con toda fuerza a sus discípulos, de donde arranca un repertorio nacionalista, con estructura y armonía románticas en el caso de los compositores más viejos, e impresionistas, en la generación ascendente, cuyos logros son un verdadero campanazo para el prestigio universal de la música española de la centuria que se desvanece.

Los años de la República apadrinan un neohumanismo en cuanto a la expansión libre del pensamiento. La Residencia de Estudiantes en el ambiente universitario, y la Institución Libre de Enseñanza en la enseñanza básica, son un claro exponente de efervescencia cultural sin cortapisas, propugnando los más avanzados sentimientos del culturismo liberal.

Los tristes hechos del 36, crean una frontera, un antes y un después. Muchos artistas, entre ellos, grandes músicos, escapan voluntariamente, buscando un exilio político-cultural. La posguerra trae consigo una fuga de talentos que deja huérfana de cultura a la España que intenta rehacerse a partir de los cuarenta.

Una patria en verdadera penuria económica; un país rehaciéndose lentamente de todo del desastre de la guerra; una vertebración laboral fundamentada en el «funcionariado», con salarios modestos. Esa es la realidad política, cultural y económica de la España de los años cuarenta.

Mas, ¿cómo y por qué surge una generación de mujeres luchadoras en una país sin medios, en el que el porvenir era incierto hasta para los hombres? 
Una minoritaria igualdad de sexos apadrinada por sectores extremos, como las socialistas Carmen Karr o María Cambrils, empalidece ante la realidad de una nueva España radical, conservadora, cerrada en sus fronteras políticas y culturales, donde se reaviva un neocatolicismo con el ideario de la familia numerosa, premiada a nivel oficial, donde el papel de la mujer consiste en llevar el timón de la casa, que no es tarea fácil.

No se puede silenciar el pensamiento avanzado de Gregorio Marañón, quien defiende abiertamente una igualdad de oportunidades intelectuales y laborales, y al apoyar el feminismo, escribe textualmente «Respecto a las aspiraciones jurídicas de la mujer, sólo espíritus atrabilarios pueden regatearle su simpatía. Es tan enorme, biológicamente, la injusticia, la inutilidad y la indelicadeza de que no sean las leyes para ambos sexos, que este, por si sólo, justificaría los mayores apasionamientos de las reivindicaciones feministas».

No he estado nunca de acuerdo con las posturas radicales de las feministas. Creo que las mujeres que no hemos renunciado a esa condición femenina con todos su atributos, al incorporarnos a la vida profesional con todo rigor, seriedad y compromiso, hemos conseguido más, que las que defienden un feminismo erróneo, queriéndose igualar al hombre. Si biológicamente no somos iguales, y físicamente tenemos atributos bien diferentes, como es bueno que así sea, ¿para qué empeñarse en una igualdad total, perdiendo la gracia femenina y convirtiéndose en unos marimachos? Es la persona la que hay que defender y salvaguardar, pero, claro está, sin la pérdida de la propia identidad.

Los cambios siempre son difíciles y a veces se plantean con posturas drásticas. La revolución femenina, que no feminista, ha supuesto en los últimos cincuenta años un paso adelante tan gigantesco para la mujer, como no se había conocido en toda la historia de la humanidad.

Si se piensa en el ambiente general de la España de la posguerra, con tanta precariedad de medios, y con una mujer sin preparación intelectual ni laboral, asustada ante el futuro cuando los padres desaparezcan y se quede sin recursos económicos para subsistir, se comprende perfectamente que la carrera de la mujer, «la verdadera carrera», no podía ser otra que el matrimonio.

Hasta tal punto, la carrera de la mujer era el matrimonio, que se consideraba una deshonra para la familia el que una sola de las hijas del matrimonio no se casara. La soltería estaba tan mal vista, que hasta había una manera de denominar a estas personas: «solteronas», adjetivo que rara vez se emplea en masculino, salvo en casos muy concretos de hombres verdaderamente raros. Sin embargo, a la mujer se le adjudica- 
ba sin piedad. Tal calificativo en femenino, además, parecía que llevaba implícita todas las cualidades más negativas que se le pueden adjudicar a la mujer; fealdad, torpeza y mal carácter.

La dependencia total de la mujer del hombre, la subordinación, la sumisión, el permiso marital exigido absolutamente para todo: vender, comprar, viajar... el paso absoluto y radical al marido, de todos los bienes aportados por la mujer al matrimonio, hacían de ella una verdadera «dulce esposa». Algunas lo llevaban con alegría, porque se habían educado en esa idea y no les parecía que podía haber otro tipo de vida; otras, por el contrario, lo sufrían con clara resignación. Todo este engranaje no era un mero aspecto social, sino que estaba refrendado por toda una Legislación en vigor desde el Código Civil de 1889, con un leve paréntesis de la Constitución Republicana de 1931, y nuevos legislaciones de posguerra «incivil», como la denominó Unamuno.

Por eso insisto en considerar relevante toda mi generación. Nuestro padres, hermanos y amigos, estos últimos potenciales pretendientes, ya exigían en esos tiempos que las mujeres de «mi clase social», tuvieran un elevado nivel cultural, que se traducía en una tolerancia en cuanto a consentir el paso por la Universidad. Eso, sí, el trámite universitario debería suponer una ilustración sin más, una licenciatura en humanidades. Filosofía y Letras, era la carrera femenina por antonomasia: ilustraba, pero sin más transcendencia. No constituía un peligro laboral y no tenía consecuencias profesionales posteriores.

Después de esta situación que creo es bastante exacta, viene la segunda parte: ¿Con qué tuvimos que luchar, pues, las mujeres de mi generación?

Aquí me gustaría hacer una detallada y ordenada exposición cronológica de los hechos y consecuencias.

Mi experiencia personal no es un caso aislado, y lo voy a relatar no por afán de protagonismo, sino para exponer un caso concreto, porque entiendo que mi trayectoria vital es una pieza más del muestrario de las mujeres de mi tiempo, fueran científicas, artistas, intelectuales o personas de letras.

Toda mi generación estaba unida por el denominador común de no querer aceptar el panorama social y laboral que hallamos y que tuvimos que luchar con tesón y gallardía para ser nosotras mismas, al margen de impedimentos, dificultades y, en muchos casos, hasta prohibiciones enérgicas.

La lucha que tuvimos que librar no fue pequeña. A cualquiera de nosotras se nos pedía y exigía infinitamente más que a los hombres para alcanzar su mismo estatus, o su prestigio y consideración. 
En mi caso, el arpa era un instrumento adjudicado, no sé por qué razón, a las mujeres, pero no para incorporarse a la vida laboral, sino para tañerlo de forma lánguida en las reuniones familiares o en alguna fiesta benéfica, pero acceder a la vida laboral era difícil.

Los honorarios de las mujeres-músicas eran siempre menores que el de los músicos, como si nosotras tuviéramos menos necesidades, y ya no en mi caso particular, por ser el arpa, «ese instrumento menor» que acabo de relatar, sino para la generalidad de las mujeres instrumentistas.

En mi caso personal, la decisión de la carrera musical fue elegida por mi madre, que amaba apasionadamente el arte de los sonidos, y que in-

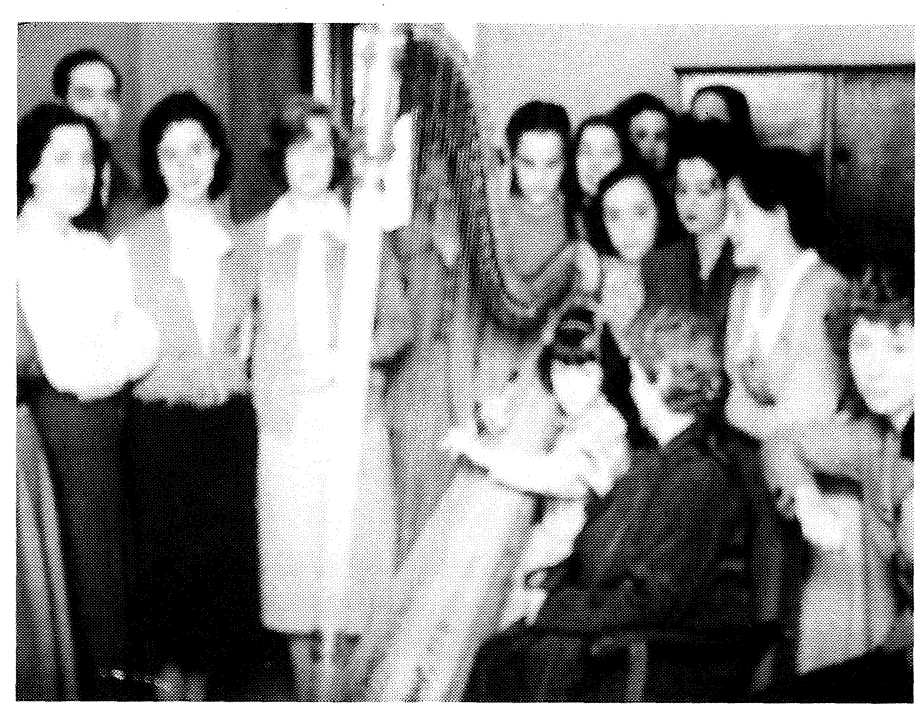

En clase, de niña. tuyó en mi persona de niña unas facultades muy específicas para el estudio de la música.

Empecé las primeras ilustraciones musicales a muy temprana edad, con cuatro años. Mi madre observó cómo yo leía la nomenclatura musical y la afinaba perfectamente, sin que nadie me hubiera enseñando, $y$, además, veía con com-

placencia cómo yo me divertía con aquella práctica. Así que decidió consultar con una experta, gran profesora de solfeo y gran persona, que influyó enormemente en mi personilla y animó a mi madre para matricularme en el Conservatorio madrileño, cosa que hacía antes de cumplir los cinco años.

Como era tan pequeña, mi madre, que sabía lo importante que es empezar cuanto antes los estudios musicales, se las agenció maravillosamente para que a mi me pareciera toda aquella disciplina, como un juego. Y así lo recuerdo.

La primera reacción de mi padre fue de tolerancia. No le parecía mal que una niña de «mi estatus social» tuviera una cultura musical, como signo de buena educación.

Hay que decir que mi madre «sacrificó» su carrera musical, por el matrimonio, aún cuando había demostrado dotes muy excepcionales 


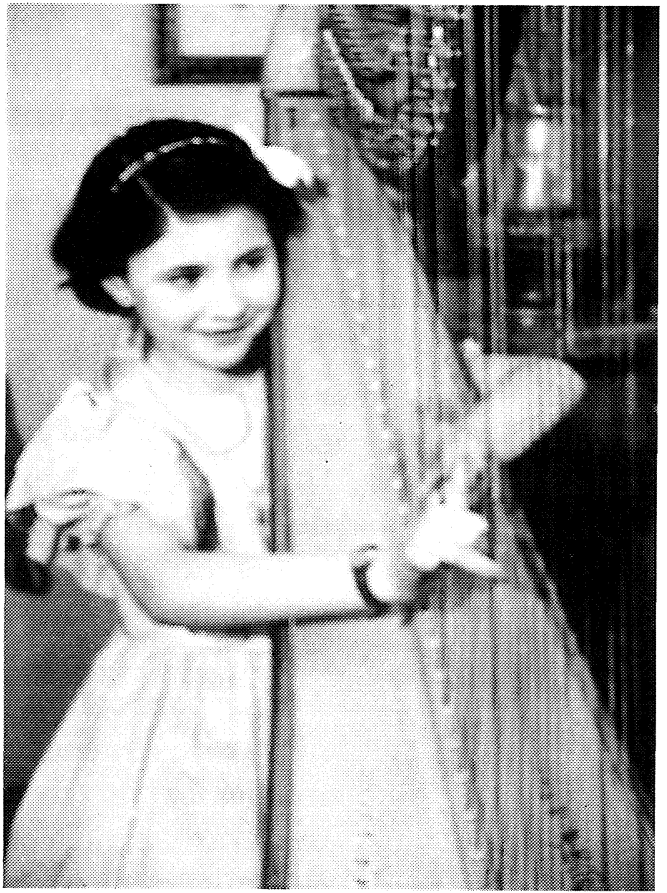

De niña preparando mi primer concierto.

para la música. A pesar de este sacrificio, fue una madre con tal dedicación a su hogar y a su familia que rayaba en los límites de lo increíble e imposible.

Mi madre había estudiado, además de la carrera de piano, la carrera completa de composición, con todas sus materias, y esto lo hacía en la década de los 20 , que, para entendernos, es algo así como que una jovencita de nuestra época se dedique a la física cuántica. (Hago esta aclaración para justificar que mi madre fue, desde el primer momento, mi más encendida aliada. Había, y ha habido siempre, como una complicidad entre las dos, hasta tal punto que con una sola mirada interpretábamos mutuamente lo que nos queríamos transmitir).

Este tipo de madre, todo hay que decirlo, ha sido la generalidad de las progenitoras de la posguerra, y, sin duda, con su saber hacer el «oficio» de madre, ha supuesto la savia fructífera que ha dado paso firme a nuestra generación. A la generación que yo he dado en denominar la «generación femenina del 65».

La inicial tolerancia de mi padre se convirtió en total, bronca y absoluta negativa, cuando, al terminar la carrera, todavía una niña, mi madre se propuso orientar y dirigir mi futuro hacia un serio camino profesional.

Hay que decir que la habilidad de mi madre fue toda una lección de maestría femenina: ora aparente comprensión, ora carácter para defender sus criterios, ora tolerante, ora decidida...

Así, en un largo camino de "estira y afloja» se fue forjando mi carrera, primero, y mi profesión, inmediatamente después, ambas con paso bien firme, pues mi madre entendía que la profesión musical hay que empezarla en cuanto se está preparado, y si yo había terminado mis estudios oficiales - los de formación no se acaban nunca en casi ninguna carrera, pero menos, aún, en la musical-, había que empezar cuanto antes a practicar para acumular experiencias, y ya de bien niña aceptó para mi 
cuantas ofertas de actuaciones llegaban a mi casa. Así, pues, desde mi más tierna infancia fui acumulando una importante experiencia. Mi madre preparó el complemento de mi formación en el extranjero. Eligió centros de estudios, instituciones, maestros, todo, y así amplié estudios en París, Siena (Italia), Holanda...

Mas, mi padre hizo dos duras imposiciones. Para él la vida del artista era una frivolidad, un forma de vida bohemia, y para la férrea formación de los varones nacidos en el pórtico del siglo que agoniza, suponía sinónimo de perdición del alma. Todo lo que se hacía en un escenario, aunque fuera música clásica, pertenecía a la farándula en el peor de los sentidos.

Para mi padre, la integridad de la persona, y eso sí que es algo que le agradezco en todo su valor, era el más preciado tesoro del ser, y había que nacer y morir conservándolo intachablemente. Su primera imposición de mi padre fue de carácter moral: viajar siempre acompañada de mi madre, para que velase por mi en todo momento. Ella lo cumplió gustosa, porque, entre otras razones, seguía más de cerca mi formación y mi trabajo.

A mi madre todo le parecía poco para que yo enriqueciera mi espíritu y mis conocimientos, y como dos infatigables «andariegas» recorrimos medio mundo en busca del enriquecimiento de mi formación, que para la década de los 60 era toda una aventura.

En una temprana edad, yo ya tenía a mis espaldas una buena cantidad de actuaciones profesionales, que se multiplicaban, bien por repetición de la misma, o porque «el boca a boca» siempre ha funcionado, y quien me contrataba y quedaba contento, me recomendaba a amigos, compañeros, y colegas. Naturalmente todas mis actuaciones eran siempre vigiladas atentamente por mi madre, que me ayuda a estudiar, corregía mis errores con infinita inteligencia y, al propio tiempo, con gran paciencia, haciéndome repetir pasajes hasta la saciedad cuando no le agradaban, dado que su nivel de exigencia era muy alto, en parte, porque sabía lo que hacía, y en parte, porque el sentido de la perfección ha sido siempre una constante en su vida.

Pero algo que recuerdo con verdadera ternura era, y sigue siendo, su forma de alentarme, sin desmayo, con infinidad de estímulos y alicientes para que la exigencia a la que me sometía, no se notara. Otro destello de su gran inteligencia.

La segunda imposición de mi padre fue de carácter intelectual. La música no era una carrera, y una dama de mi clase social tenía que formarse, debía tener nobleza de corazón y de formación. Así que, a pesar de mi durísima vida de adolescente, ya concertista muy activa, con fama de «niña prodigio», viajando, estudiando y trabajando, no me libré del 
paso obligado por las aulas universitarias por las que tenían que pasar las mujeres de mi generación, si es que deseaban obtener el marchamo de «cultas».

Sí, yo también debía tener el título universitario en la Licenciatura de Filosofía y Letras, como todas las jovencitas españolas de la década de los sesenta. Mi padre no comprendía, o no quería comprender, que la música, como carrera, era tan dura y tan larga, que los músicos de mi generación no tenían tiempo para hacer el bachiller, y que, como no era obligatorio, nadie lo hacía. Pero mi padre se hacía el sordo a las dificultades e imponía su voluntad, y tuve, cómo no, que simultanear el bachiller, primero, y luego la carrera, que me vi obligada a simultanear entre la Complutense y la Sorbona.

Pero he de decir, en honor a la verdad, que agradezco la decisión de mi padre, pues, para entendernos, esa preparación me ha hecho ser una artista más humanista, lo que no es nada despreciable. Estudiar filosofía ayuda a pensar, y la estética artística, que se fundamenta en la filosofía, es más profunda cuanto más sólida es la formación.

Se dice y repite que la intuición es la quintaesencia del arte, y aunque es muy gratificante ser artista nato, no es menos cierto que, cara a la madurez, cuanto más formación tiene el artista, esa intuición, esa naturalidad artística, se ampara en pilares más firmes. Es decir, que en lo referente a formación, aunque reconozco que tuve una juventud más que activa y acelerada, todo son loas para mis progenitores; entre exigencias, comprensiones mutuas entre mis padres, y tolerancia final por parte de mi padre en la decisión de mi porvenir, forjaron un carácter férreo, que me ha servido para saber siempre, y en todo momento, lo que quiero, $\mathrm{y}$ hacerlo sin perjudicar a nadie, y sin hacer daño a lo que tiene que estar siempre bien templado: El espíritu.

Mi periplo de estudios en el extranjero se truncó precipitadamente por una historia tan bella como jamás, hasta entonces, había vivido. Atrás quedaban los estudios aquí y allá, los premios internacionales en las competiciones mundiales de arpa, los éxitos primeros de juventud, las carreras del Conservatorio parisiense y La Sorbona, amén de las escapadas a grabar en los diversos programas de la ORTF, mientras desarrollaba mi trabajo temporal en la biblioteca del Centro Cultural de la Embajada de España en París.

Se convocan oposiciones para la flamante Orquesta de RTVE, y naturalmente, aquella oportunidad no la podía perder. Aunque me obligaba a abandonar, con no poco dolor, mi periplo de estudiante, debía intentar, por todos los medios opositar aunque no tenía muchas esperanzas en los resultados porque, para empezar, tenía que conseguir una dispensa de edad. 
La suerte estaba de mi parte. Todo salió bien, y me convertía en una jovencita de sueldo millonario. En la España de los sesenta un Catedrático de mi especialidad ganaba 1.300 pts. al mes; la orquesta de RTVE anunciaba en su convocatoria un sueldo quince veces mayor.

Cuando acababa de salir de las durísimas pruebas de la orquesta, se convoca la plaza de la Cátedra de Arpa del RCSM de Madrid. Por gracia de la fortuna, y no con poco esfuerzo, pues no recuerdo otra constante en mi vida que «trabajo, trabajo y trabajo», me convertía en la Catedrática más joven de la historia de España, desde los tiempos de Menéndez y Pelayo.

Hay que recordar que la Orquesta de la Radiotelevisión Española, creada por el entonces Ministro de Información y Turismo, Manuel Fraga Iribarne, con un sentido auténticamente futurista, dignificando de una manera oficial la profesión de la música,(que hasta entonces estaba mal vista, y no sólo por mi buen padre, sino por toda la generalidad de la vida cultural española), con sueldos millonarios, fue un primer aldabonazo para reconsiderar la vida profesional del músico como algo digno y serio.

No cabe duda que el sueldo era una forma oficial y, a la par, material, de propulsar esa dignificación, pues hasta entonces los pobres músicos españoles, eran unos bohemios que se dedicaban a hacer «bolos» para poder subsistir, lo que les dejaba completamente exhaustos y les quitaba tiempo para seguir estudiando, con lo que arruinaban sus carreras y precipitaban su final absoluto.

Fue tal revulsivo la creación de la Orquesta de la RTVE, que la veterana Orquesta Nacional Española, creada por el Ministerio de Educación al terminar la contienda española, con precariedad de medios, se sintió estimulada por su «hermana pequeña». En efecto, no tardó en mejorar sus sueldos, equipar su material instrumental, dotar a los músicos de unos uniformes dignos, mejorar las condiciones de ensayo, que hasta entonces se hacían en un espacio destartalado del cerrado Teatro Real sin calefacción, (recuerdo cómo se calentaban, en el duro invierno, con unas estufas improvisadas), y con un acceso a través de unas escaleras de ladrillos sin acabar de enfoscar.

Yo me imagino la lamentable impresión que tal situación produciría a los artistas invitados, como los grandes directores del mundo, que ya entonces empezaban a venir, no con pocos sacrificios para el Ministerio de Educación, escaso hasta decir basta, de medios económicos.

Seguimos en la década de los sesenta. Como los profesores de la Orquesta Nacional eran funcionarios del Ministerio de Educación y Ciencia, no hubo más remedio que equiparar los sueldos de los Catedráticos de Conservatorios a los de la ONE, puesto que pertenecían igualmente al 
MEC, y tenían el mismo estatus laboral. Era tan curiosa la situación económica de los músicos españoles de los principios de los años 60, que aparecieron infinidad de publicaciones hablando de «la música en cifras», que no se refería, naturalmente, a la nomenclatura musical del «cifrado» y sí a los ridículos sueldos de los músicos españoles.

De toda esta exposición es fácil deducir que nuestros padres no quisieran la música como profesión para sus hijos, y aquí ya sin diferencia de sexos, pues parecían estar abocados a una vida precaria y dura, sin reconocimiento social ni laboral.

No cabe duda que el reconocimiento social y laboral, en buena medida está en relación a los salarios, por eso hay que decir con justicia que

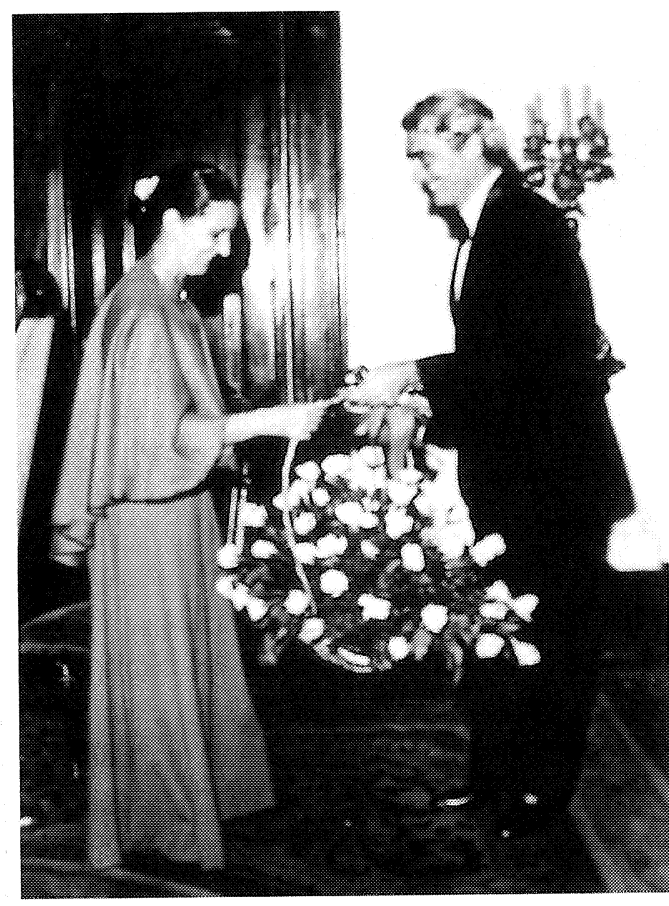

Concierto en Río de Janeiro recibiendo un ramo de flores del entonces cónsul general de Río, hoy embajador Abella. la creación de la Orquesta de RTVE dignificó de manera social la profesión musical.

Aparecer la flamante orquesta todas las semanas en la pequeña pantalla, maravillosamente uniformada, (quiero decir, vestida), con un material impecable, con unos decorados cuidados en los que no faltaban los adornos florales, hizo que, poco a poco, se fuera metiendo en las casas (en un momento que la televisión empezó a convertirse en un artículo de primera necesidad) una nueva imagen sociocultural de los músicos. De un plumazo, a las puertas de la década de los 70, la vida musical española, desde su aspecto profesional, empezaba a tener otra consideración.

Pero volviendo a mi trayectoria: en la España de 1965, con una dura censura, y un control policial férreo, centralizado por el sistema político de la Dictadura, donde el orden estaba garantizado desde el Estado, no se producían muchas noticias. Así pues, mis galardones a tan temprana edad, era todo un «noticiazo", digno de toda publicidad y publicación. Llené las páginas de todos los periódicos, revistas y cómo no, otros medios de comunicación. Ahora, seguro que 
toda esa publicidad hubiera costado una millonada, pero en aquellos, mis tiempos juveniles, era toda una noticia. Como miembro de la Orquesta de RTVE, no podían faltar, y no faltaron, entrevistas y diversos programas, de todo tipo, en Radio y TVE1, la única cadena que existía entonces, que, como todos recordarán, se emitía en blanco y negro.

Tampoco faltaron las anécdotas. Mi madre, mi más entusiasta admiradora, como no teníamos televisión en casa, casi nadie la tenía en aquellos momentos, pues los artículos de primera necesidad eran muy distintos a los de ahora, se las agenciaba para ir a una cafetería donde hubiera instalada la pequeña pantalla, y con el pretexto de merendar, esperaba los programas en los que salía su hija. Pero nuestra España,

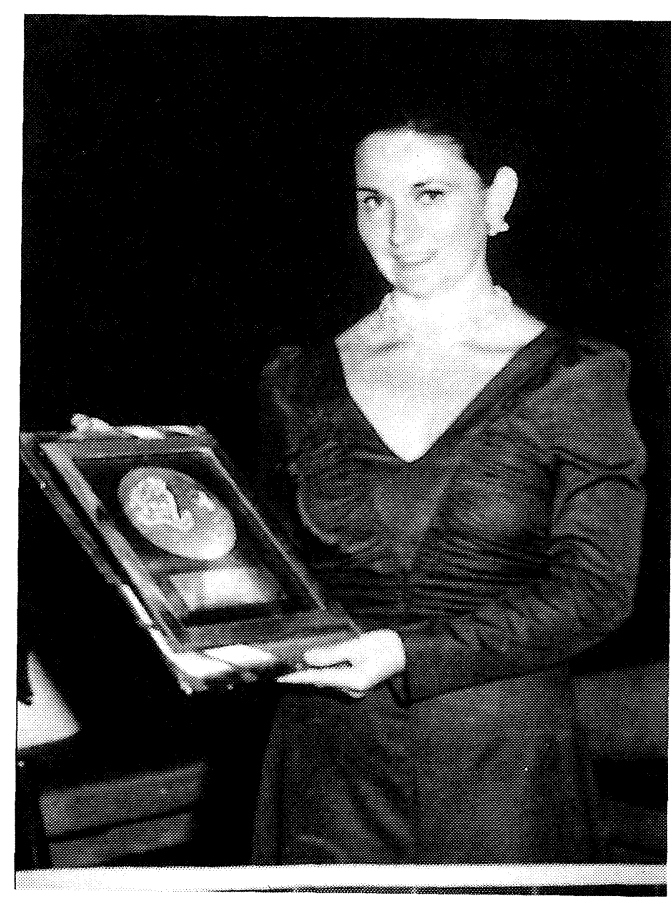

Recibiendo el «Aguila de Tlatelolco» de la Secretaría de Relaciones Exteriores, como premio a la labor desarrollada en Méjico. que siempre ha sido muy futbolista, lo único que interesaba ver en TV era el partido, y cuando éste se acababa, siempre había un camarero que apagaba el aparato, pretextando que el programa musical que seguía era un rollo. No sin la protesta de mi madre, que algunas veces, entre vergonzosa $y$ decidida, decía, por favor, no lo apague, que ahora va a salir mi hija y quiero verla.

La noticia era, o la hacían, espectacular: «Una jovencita que toca un instrumento tan raro como el arpa, se ha convertido en la catedrática más joven de España».

Tanta publicidad me hizo famosa, me reconocían por la calle, en el teatro... Yo estaba como flotando en el espacio: al esfuerzo compensado, se unía el hecho, nada desdeñable, pero difícil de asimilar para una jovencita, de la publicidad y la fama.

Pero en esos momentos, también estuvo mi madre alerta para que mi cabeza siguiera serena y equilibrada. Contra soberbia, humildad, me repetía. Y además, apostillaba, eres tan joven, que todo lo que has hecho no es nada comparado con lo que te queda por hacer en toda tu vida, así que 
mira hacia adelante, y ponte a estudiar como lo que eres, una jovencita que tiene mucho que aprender todavía.

Pero ese éxito y esa fama tenían su contrapartida. ¿Cómo era visto por mis amigos masculinos, por mis compañeros de trabajo?

Empezaré por decir que ya era visto de una forma excepcional el que una jovencita saliera al extranjero en los años sesenta, conociera mundo y aprendiera otro idioma. Mis amigas lo veían como algo envidiable en el de mejor de los sentidos, pero los chicos lo veían como un principio de independencia que no les agradaba demasiado.

Mis amigas se sentían orgullosas, y aunque sentían una sana envidia, porque no era fácil salir al extranjero en una España con escasas posibilidades económicas, parecía que ya empezaba a sentirse una conciencia social femenina, por la que nos hacía estar unidas en la causa. Lo que una hacía de bueno, o suponía un paso hacia adelante, era jaleado por la comunidad de amigas $\mathrm{y}$ compañeras.

Mis amigos, la sección masculina, me refiero, tuvieron, ¿cómo explicarlo?, una especie de

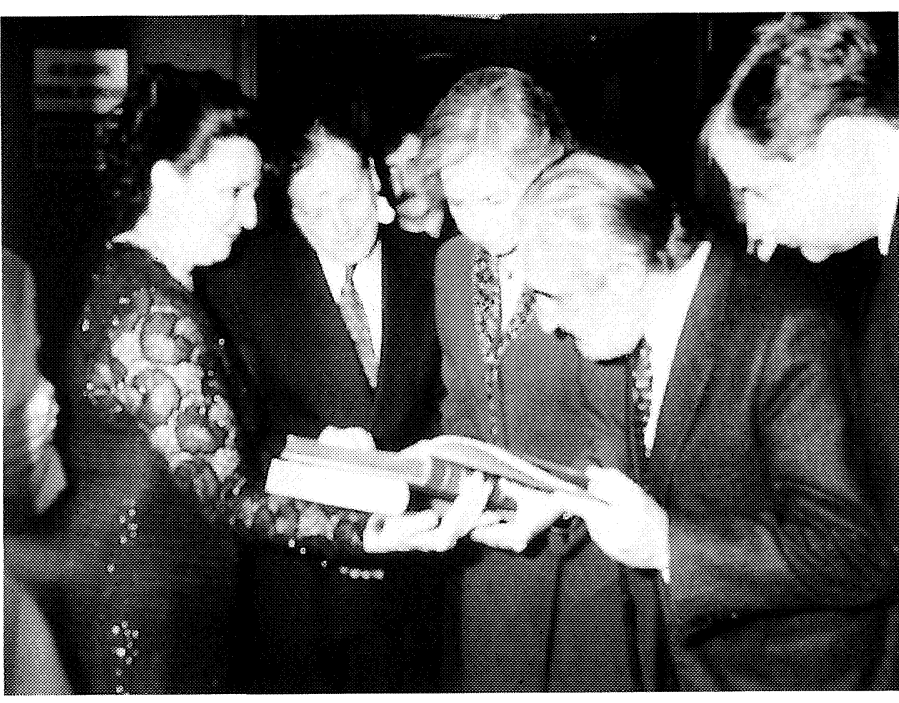

Haciendo entrega a S.M. la Reina de un trabajo dedicado a ella, en presencia del alcalde Alvarez del Manzano y otras autoridades. «escapada» colectiva.

Los nuevos que se acercaban a mi, al reclamo de mi fama, lo hacían, como si vinieran a conocer a un «bicho raro», y tenían que comprobar cómo sentía, cómo pensaba, cómo era...

Con los amigos antiguos que conseguía dialogar y a los que preguntaba por qué huían de mi, mostraban tal complejo, que resultaba grotesco. Todos ellos, mayores que yo, eran todavía estudiantes, no disponían de otro dinero que el reducido «salario» de papá, que entonces era ridículo, mientras que yo estaba brillantemente situada, se sabía que ganaba mucho dinero, era independiente económica y personalmente, y el hombre de hace cuarenta años, evidentemente machista, no podía comprender que la mujer despuntara en nada absolutamente. 
Los que me declaraban su amor, lo hacían con un tono tan imperativo que producía nauseas: "cuando nos casemos abandonarás la vida artística, ¿verdad?».

He de decir, que aquellos amigos que huyeron de mi cuando era una jovencita triunfadora, han vuelto al cabo de los años, con una amistad que impresiona por la profundidad de sentimientos y por la nobleza de acción. Es decir, no es que algo esté cambiando, están cambiando, y muy deprisa, mucha cosas.

Los compañeros de trabajo, por el contrario, no participaban de mis alegrías cada vez que yo, ingenuamente, creía que podía compartir con ellos mi gozo, contando mis actuaciones. Pero no era así, pronto observé que lo que para mi era una alegría para ellos suponía una gran tristeza. Qué es la envidia, sino la tristeza del bien ajeno.

Cuando una persona elige su profesión, y hace todo tipo de sacrificios para alcanzar las metas propuestas, no hay nada en el mundo que pueda compensar esa decisión tan férrea. Hay espejismos, cómo no. La ilusión del matrimonio, a cuyo estado se iba antes con tanto grado de ignorancia, parecía que era lo suficientemente fuerte como para anular cualquier otro deseo. Pero bien es verdad, que esa ilusión, y aún estando cimentada en un amor verdadero, acaba por dejar aflorar el sentimiento primario de lo realizado y alcanzado antes del casamiento. Cuántas mujeres se han lamentado de dejar su profesión, $y$, si han podido, han vuelto a integrarse en ella en cuanto han tenido oportunidad, o los hijos han empezado a crecer, y se han visto literalmente solas en casa.

Pues si la mujer de cualquier profesión siente nostalgia de ella en cuanto se desvanecen las ilusiones matrimoniales, cómo serán los sentimientos de las de las músicas, cuyo arte anida fuertemente en el espíritu del ser desde la más tierna infancia, y es algo que se convierte en consustancial a la propia vida.

La ruptura de la sumisión de la mujer, ha sido muy bien reflejada en esa obra magnífica como es Casa de Muñecas, de Ibsen, cuando, la protagonista, Nohora, dice: «No es tarde todavía, Siéntate, Torvaldo: tenemos que hablar». Para muchos críticos es el principio del teatro de diálogo, pero para otros muchos supone un nuevo talante de mujer que saturada de sumisión, empieza a poner de relieve sus valores como persona.

El hombre ha sido duro, y ha argumentado su dureza como signo de sus cualidades masculinas, pero si el amor es compartir, es vivir los dos en uno, ¿qué hombre puede ser feliz viendo desgraciada a su mujer?

Yo he sido testigo de infinidad de amigas y compañeras que trataron de simultanear el matrimonio con su vida artística, ante una aparente aceptación de un hombre que parecía comprensivo con la realización de 
su carrera, y han vivido un infierno de celos en su matrimonio, que ha terminado en divorcio.

Los celos artísticos son los peores, pues es difícil de soportar, cuando el hombre es celoso por naturaleza, el que su mujer sea vista, aplaudida y halagada por todos antes sus propios ojos. El dicho popular, de «la mujer en casa y con la pata quebrada», define muy bien el machismo del

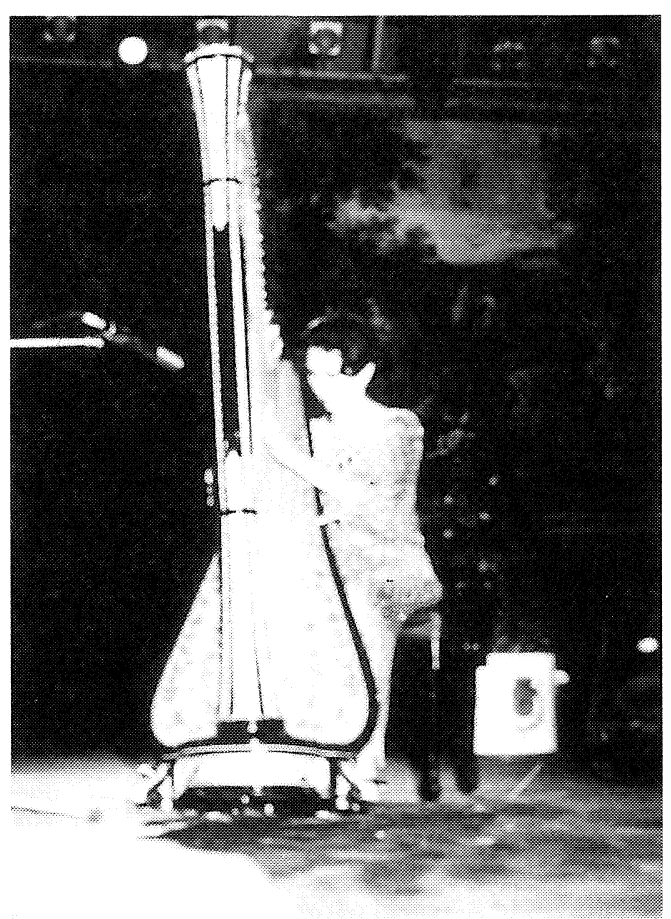

En el Palacio del Pardo. hombre carpetovetónico, en cuyo sentimiento él ha tenido siempre «bula» para hacer todo tipo de devaneos, pero su mujer, su hermana y su esposa tienen que tener una intachable conducta.

En la década de los sesenta, se pasó del amor irreflexivo, por el que al primero que solicitaba matrimonio se le aceptaba ante el temor de que no viniera otro, y no se analizaba si había amor, cariño o conveniencia, aunque en el mayor de los casos la mujer era una desgraciada, porque se había casado ante el miedo a la vida, sola y sin medios, y terminaba refugiándose, no en el amor, y sí en la conveniencia, y, una vez dado el paso, el único sentido de vida era la dedicación amorosa a los hijos; al amor sosegado y reflexivo, donde se empezaban a analizar los entras y los contras, y, sobre todo, se empezaba a analizar fríamente si había verdadero amor.

Bien es verdad que donde hay verdadero amor, ese mismo amor hace el milagro de que la convivencia no desgaste, de que ambos se enriquezcan con la sabiduría del otro, y cualquier contrariedad se soporta en virtud de ese amor, que enriquece el sentido de responsabilidad.

Pero para tal reflexión, hay una cosa imprescindible: que la mujer sea verdaderamente libre para optar libremente al matrimonio. Una formación que capacita a la realización de la profesión, es un principio de independencia de la mujer. Quizá el hombre, intuía esta situación, o, sin intuirla, su carácter machista no le permitía aceptar la realización de la mujer. Quién sabe lo que pasaba por la cabeza de los hombres de hace cuarenta o cincuenta años. 
Música o matrimonio. Historia oculta de la mujer-música...

Pensemos lo difícil que es para un hombre ibérico aceptar la profesión de la mujer siendo concertista, cuando dicha profesión se ejerce en un escenario: ¿qué hombre puede ver con gusto que la mujer, su mujer, y si además, es agraciada, se luzca para que la vean los otros?

Siempre he dicho que a mi me han perjudicado tres cosas fundamentalmente para mi carrera: Ser mujer y con fama de guapa, quedarme a vivir en España, y tener como profesión tañer el arpa. Aunque no cambiaría mi vida por nada ni por nadie; soy una persona auténticamente feliz con lo que tengo, que creo que es mucho lo que la vida me ha dado.

Ser mujer con fama de guapa me ha planteado serias dificultades porque todavía hay un sector machista que cree que la mujer no puede tener éxito por méritos y esfuerzo propios, y sí gracias a cierto tipo de contraprestaciones. Es ese tipo de hombres, que muchas artistas nos hemos encontrado, $\mathrm{y}$ al que hemos tenido que mostrar firmeza y seriedad para alejarlo y dejar bien clara nuestros planteamientos.

Quedarme a vivir en España, también me ha hecho daño porque para la mentalidad latina, y sobre todo española, nadie es profeta en su tierra. Todos conocemos artistas de gran valía que han tenido que abandonar la patria para hacer su carrera, porque aquí nadie les hacía el menor caso. Hay que recordar lo que decía el «Españoleto», España es madre amante para los extranjeros, y madrastra dura y cruel para los de casa.

Tener como profesión tañer el arpa, creo que ha sido un gran prejuicio. El arpa siempre ha estado asociada a la mujer, pero, naturalmente, sin carácter profesional.. Yo tenía un profesor de Filosofía que decía y repetía, y no sé si me lo dedicaba a mi por ser su alumna y saberme música, que las mujeres sólo servíamos para tres cosas: cocinar, hacer trapos y tocar un instrumento, aunque los mejores cocineros, los mejores modistas y los mejores músicos siempre han sido hombres.

Recuerdo una anécdota que enlaza con el punto uno que acabo de analizar. Cuando gané la cátedra entre el asedio de periodistas, vino un corresponsal de una revista extranjera muy famosa ya en aquellos años, que me propuso hacer un gran reportaje, en el que se reflejara mi vida cotidiana: En casa, estudiando, saliendo con amigos, y en un club deportivo para fotografiarme jugando al tenis, $y$, aquí viene lo mejor, en bikini, para sacarme en la portada tirándome a la piscina desde un trampolín. Como todos Vds. se pueden imaginar, le aclaré muy bien al periodista que ganar una cátedra me había costado un gran esfuerzo, y que estaba equivocando las cosas. Yo no era una modelo para lucir mi cuerpo en ninguna parte, y sólo, por el contrario, una chica seria, que toda su vida, por corta que todavía era, se había centrado en el temple del sacrificio para lograr sus metas. Como es natural, aquí se acabó la 
historia con el tal periodista. Ese día sentí por primera vez, el orgullo de haber llevado a la práctica los consejos de mi padre sobre la dignidad, y, puedo asegurar, que me sentí como elevada.

Mi generación, que era completamente ingenua, sin saber nada de la vida hasta bien mayores, nos sentíamos ofendidas y a veces, casi no acertábamos a entender nada, cada vez que se presentaba un «mafioso» tratando de deslumbrar.

La generación actual sabe mejor lo que quiere, y hace las cosas, si es que se presta a ellas, con otra mentalidad. Aquí hay que volver a alabar a las madres de los 60, que estaban cerca de las artistas que hacían vida activa, pues fueron maravillosos frenos, como un pararrayos que evitaba cualquier peligro.

La vida artística, que es preciosa para quien la siente, tiene sus contrapartidas: cansancio por los constantes viajes, a veces con poco tiempo para dormir, la constante exposición nerviosa ante la tensión que supone la actuación pública por más experiencia que se tenga, invitaciones extemporáneas antes de un concierto, que desgastan porque absorben la concentración necesaria para una buena actuación... éxitos fáciles que deslumbran de la misma manera que lo hacen las luces de las candilejas, halagos de críticos, de público, de amigos...Hay que tener el alma bien templada para no dejarse marear por tantas situaciones estimulantes que excitan la delicada sensibilidad del alma del artista y que, en la vida artística, se dan constantemente y, casi siempre, de forma precipitada.

Es difícil comprender desde fuera, la euforia, la inmensa alegría que se siente al terminar ese largo ciclo de preparación, en verdad, severa, que supone un difícil programa de concierto: la concentración durante meses, el esfuerzo de memorización de la partitura con todos su detalles, más, al terminar el concierto, donde la tensión emocional, la pasión de la interpretación para atrapar la atención y el sentimiento del público, ha sido inmensa, a lo que se une la borrachera del éxito con los aplausos..., todo ello supone una aceleración tal del sistema nervioso que todo el organismo sufre una alteración metabólica, que se traduce en un brillo especial en los ojos, la frente y las mejillas, que puede inducir a equívocos al «macho» que observa desde fuera. Si la artista está lejos del hogar, y, por tanto, del cariño de la familia, la necesidad de compartir es tan grande que el que se acerque va a sentir una irradiación especial, que en origen no es otra que todo lo que acabo de relatar, pero que puede dar lugar a equívocos.

Creo que para concluir este artículo, se podría concretar el papel de la mujer del siglo que agoniza dividiéndolo en tres claras generaciones: 1. la de mi madre, sacrificada, pero reflexiva y transmitiendo pensamientos de dignidad de la mujer como persona. 2. La mía, la generación puente, no 
Música o matrimonio. Historia oculta de la mujer-música...

comprendida por padres, hermanos y amigos. Más aún, yo me atrevería a decir que ha sido una generación incomprendida por todos, porque es difícil que una jovencita de hoy imagine, ni por un instante, lo que era el papel de la mujer de hace, a penas, cuarenta años. 3. La generación actual, decidida en sus proyectos personales y eligiendo al hombre como antes lo

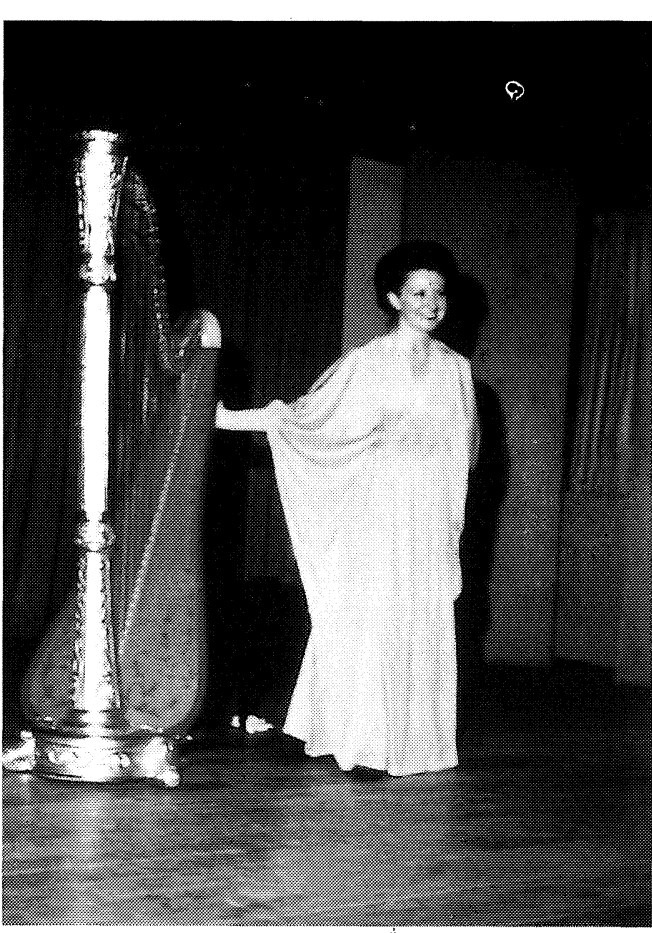

En el Carnegie Hall de Nueva York, el día de mi debut alli. hacían ellos.

Concluyo agradeciendo, públicamente, los principios educativos de mi padre, y los mensajes constantes de mi madre como una glosa diaria del pensamiento paterno. A ambos, nunca daré suficientemente las gracias, porque la persona nace, y la profesión se hace.

Como en una glosa de homenaje a mi padre, debo confesar que me reconcilié con él, en el aspecto artístico, justo en el pórtico de su muerte. Sí, ante una larga gira por Estados Unidos, incluido el debut en el Carnegie Hall neoyorquino, mi padre, curiosamente, mostró una gran ilusión por este nuevo evento, y sin embargo, Dios le llamó a su morada, justo la víspera de mi salida para USA. $\mathrm{Ni}$ que decir tiene, cómo toqué en aquel concierto, con el alma rasgada de dolor, y sin ninguna preocupación por lo que representaba tan importante recital. La crítica dijo que había habido algo sobrenatural en aquel concierto; fue el éxito más grande que he tenido en mi vida, y yo creo firmemente, que mi padre hizo, espiritualmente, aquel concierto.

Mi padre me repetía constantemente: «Dama y caballero sólo son los que tienen verdadera dignidad, y la DIGNIDAD, así en mayúsculas, es lo único importante en la persona. La carrera y la profesión son una pura anécdota en la vida, que depende de las situaciones, circunstancias y oportunidades». Mi padre añadía: «recuerda siempre hija, que el señorío, es decir, comportarse en todo momento como una dama y un caballero, no tiene jamás vacaciones, ni un minuto en toda la vida». En homenaje a mi padre, he procurado siempre no tomarme esas vacaciones. 